Memórias de violências: Que futuro para o passado?

\title{
Memórias de violências: Que futuro para o passado?
}

Maria Paula Meneses

\section{OpenEdition}

Journals

Edição electrónica

URL: http://journals.openedition.org/rccs/5867

ISSN: 2182-7435

\section{Editora}

Centro de Estudos Sociais da Universidade de Coimbra

Edição impressa

Data de publição: 1 maio 2015

Paginação: 03-08

ISSN: 0254-1106

Refêrencia eletrónica

Maria Paula Meneses, « Memórias de violências: Que futuro para o passado? », Revista Crítica de Ciências Sociais [Online], 106 | 2015, posto online no dia 28 abril 2015, consultado o 22 setembro 2020. URL : http://journals.openedition.org/rccs/5867 


\section{Memórias de violências: Que futuro para o passado?}

Vivemos num mundo profundamente marcado por encontros culturais, pela colonização, lutas nacionalistas e violência das guerras civis. Estes processos não só marcam a distribuição da riqueza, do poder e do conbecimento a nível global, como também afirmam as atuais fronteiras nacionais, influenciando os regimes sociojurídicos que governam as vidas das pessoas, gerando novos debates sobre o conteúdo político das narrativas fundacionais dos 'novos' territórios políticos resultantes das lutas emancipatórias nacionalistas. Porém, o impacto do moderno projeto colonial aconteceu não apenas a nivel da implantação do Estado moderno; pelo contrário, marcou as formas de narrar e definir uma berança que ainda hoje se faz sentir.

A compreensão dos contornos atuais dos debates históricos sobre os Estados-nação pós-coloniais em contexto africano abre campo para problematizar as opções e as raízes das razões que transformam a delimitação de fronteiras $e$ as políticas de pertença e cidadania em espaços de conflito aberto. A utilidade beurística de conceitos como 'nação' depende muito da forma como estes são utilizados para explicar e justificar os processos e práticas sociais e políticas especificas, quer hoje, quer no passado. Em contextos como os de Moçambique, Angola ou Congo, o problema reside em saber em que consiste a integridade nacional, em questionar os sentidos de pertença e as suas implicações morais e materiais. Justamente porque estas questões são tão reais e imperativas que ganham força e sentidos que impelem a uma reflexão mais profunda.

Os textos que integram este volume da Revista Crítica de Ciências Sociais ${ }^{1}$ são produto de reflexões desenvolvidas no âmbito de projetos de investigação

\footnotetext{
${ }^{1}$ Este número foi organizado em articulação com vários projetos de investigação desenvolvidos no Centro de Estudos Sociais (CES) da Universidade de Coimbra-Laboratório Associado, nomeadamente: "ALICE, espelhos estranhos, lições imprevistas", coordenado por Boaventura de Sousa Santos, que recebe fundos do Conselho Europeu de Investigação, 7. Programa Quadro da União Europeia (FP/2007-2013) / ERC Grant Agreement n. ${ }^{\circ}$ 269807; "ALCORA - Alianças secretas e mapas imaginados: a Guerra Colonial Portuguesa no xadrez da África Austral” (PTDC/AFR/121404/2010-FCOMP-01-0124-FEDER-019531) e os "Os Comprometidos: questionando o futuro do passado em Moçambique" (PTDC/AFR/103057/2008 FCOMP-01-0124-FEDER-008664). Estes dois últimos contaram com o apoio, via FEDER, do Programa Operacional Factores de Competitividade (COMPETE) e de Fundos Nacionais através da Fundação para a Ciência e a Tecnologia (FCT). O número conta igualmente com a experiência do projeto "Vidas marcadas pela história: a Guerra Colonial Portuguesa e os deficientes das Forças Armadas" (PTDC/ CS-SOC/118305/2010-FCOMP-01-0124-FEDER-019877), coordenado por Boaventura de Sousa Santos. Um agradecimento profundo a todos e todas os/as que participaram nos vários eventos académicos associados a estes projetos e cujos comentários e sugestões ajudaram, em múltiplos momentos, a tecer as narrativas dos textos que integram este volume.
} 
que procuram debater as possibilidades da descolonização e democratização da moderna historiografia. No seu conjunto, estas reflexões procuram contribuir para uma ampliação metodológica e epistemológica sobre as latências coloniais para além das independências políticas (Santos, 2006). Estas análises, cujo epicentro se encontra em Moçambique, nos últimos 50 anos, somam-se a um crescente número de debates académicos e políticos que enfatizam a necessidade de interpretar os impactos da economia política da situação colonial (Balandier, 1951) a curto e longo prazo, numa interseção de fatores locais, nacionais e globais.

Apesar de os textos incidirem especialmente sobre Moçambique, outros territórios estão presentes neste volume. O facto de Moçambique, Guiné-Bissau e Angola terem sido colónias de Portugal marca, sem dúvida, o campo das narrativas sobre a construção destas nações, mas não termina nem se encerra apenas nestas relações. Paralela à criação de África enquanto projeto imperial, a apropriação de 'novos' territórios pela ação da geopolítica moderna surge associada à emergência de um Portugal que era parte de um projeto imperial europeu. Do outro lado, como importa sublinhar, a bistória, especialmente da luta armada, mantém-se um elemento fundamental de estruturação dos sentidos de pertença a projetos nacionais recentes. Uma avaliação de vários eventos ligados à situação colonial e à transição para as independências revela, em simultâneo, aspetos esquecidos elou silenciados sobre o passado - como a situação dos diminuídos físicos das Forças Armadas, uma das consequências da Guerra Colonial/Guerra de Libertação Nacional - mas também sobre as dúvidas presentes e a realidade que as acompanha (Sarlo, 2007).

Como os textos sugerem, as narrativas contemporâneas encerram vários paradigmas, por vezes conflituais entre si: o paradigma colonial, o anticolonial e o nacionalista. Em tempos modernos, a expressão mais visivel das narrativas opostas à oferecida pelos colonizadores foi a grande narrativa gerada pela luta nacionalista, centrada na denúncia do colonialismo e dos seus vícios e na elaboração de um projeto nacional de futuro (Andrade, 1998). Esta narrativa, repleta de promessas para o futuro, evitou e continua a evitar diálogos com o passado. É este o projeto que está, como vários textos analisam, na origem da ideia de Moçambique para os moçambicanos e moçambicanas. Este projeto, apelando à igualdade, provocou, de forma dramática, o apagamento das diferenças culturais e políticas que formavam o tecido social do país, gerando profundas contradições, sinónimo de continuidades com mecanismos de dominação modernos, cuja ação se continua a fazer sentir (Meneses, 2008).

Os artigos estão organizados de forma a interligar os fios fornecidos pelos sujeitos e temas que abordam, e que se repetem e repercutem em vários momentos. 
A partir de locais múltiplos de construção e interpretação bistórica, estes textos procuram reabilitar sujeitos - individuais ou coletivos - e eventos, de acordo com a especificidade da sua relação com as várias facetas dos projetos políticos em confronto. As histórias plurais em diálogo relatam-nos contactos e continuidades, e são tanto mais crediveis quanto construidas através de debates e análises escrupulosas de várias perspetivas e situações, alargando o reconhecimento da diversidade epistémica do mundo, quando, em simultâneo, põem um fim a qualquer das teleologias existentes.

Em "Xiconhoca, o inimigo: Quem eram (são) os inimigos da revolução moçambicana?" Maria Paula Meneses analisa vários eventos, violentos, sobre os quais assenta o projeto de nação em Moçambique. O artigo discute a tentativa da criação do 'bomem novo' no contexto de um jovem país independente, avaliando a continuidade da presença da figura do inimigo interno, representado pelo Xiconhoca. O artigo aborda igualmente a centralidade da figura do inimigo interno a partir da análise de várias reuniões de busca de verdade e de reconciliação realizadas em Moçambique entre 1975 e 1982, discutindo em detalhe o contexto político-ideológico em que estas reuniões aconteceram, assim como as suas implicações no contexto da construção da cidadania e da história oficial de Moçambique.

Benedito Machava debate, no seu artigo sobre o episódio do 7 de Setembro de 1974, o papel de um grupo de resistência africana, abrindo caminho para uma reflexão mais ampla em torno da dialética dos processos de descolonização. A solução deste episódio menos conbecido do processo de transição para a independência em Moçambique foi possivel, entre outros aspetos, graças à participação ativa das elites africanas urbanas. Analisando o imaginário político destas elites urbanas, o artigo descreve o papel que estas desempenbaram no desarmar de uma tentativa de golpe -7 de setembro - e na proteção das populações africanas, evitando deste modo o escalar da violência em Lourenço Marques.

A ligação entre a literatura, o cinema e a história está no centro do artigo de Fabrice Schurmans, cuja análise se centra nas obras Une Saison au Congo, de Aimé Césaire, e Lumumba, de Raoul Peck. Para o autor, a relação intima entre a história e a ficção permite que a literatura possa, num patamar mais amplo, relatar a história, tocando no cerne de um debate central às ciências sociais e bumanas. A literatura e o cinema desempenham um papel importante não apenas na transmissão de uma memória truncada, dominada durante muito tempo por uma historiografia de origem colonial, mas também na edificação de um outro discurso histórico. Como Schurmans sublinha, não se trata de pôr em evidência a relação entre literaturalcinema e história, mas de questionar especificamente a natureza desta relação na atualidade. 
O tema da memória é retomado por Bruno Sena Martins, num texto intitulado "Violência colonial e testemunho: para uma memória pós-abissal". Partindo da problematização dos silenciamentos presentes em histórias de vida de "deficientes das Forças Armadas", o autor desafia as modernas narrativas nacionais, analisando as lutas pelo sentido trazidas pelas suas narrativas. O texto procura, por um lado, dar a perceber os termos de um confronto entre uma memória da violência, corporalmente inscrita, e a denegação da violência colonial no senso comum do Portugal democrático. Por outro lado, procura compreender de que modo a noção de uma guerra evitável e injusta, crescentemente sedimentada após o seu ocaso, cria um paradoxo para aqueles que, tendo sido parte de uma força agressora, se configuram como vítimas.

Ungulani Ba Ka Khosa procura com o seu texto contribuir para o debate sobre as políticas identitárias no Moçambique contemporâneo. Contrapondo a diversidade identitária do tecido social do país à altivez ignorante das estruturas de poder presentes no mesmo país, o texto problematiza, em vários momentos históricos, a fratura cognitiva entre o projeto político nacional, conceptualizado a partir das elites que controlam o Estado, e o plurilinguismo e a polifonia que constroem o tecido social real.

No seu texto sobre memória, história e narrativa, Teresa Cruz e Silva expande os desafios à escrita biográfica no contexto da luta nacionalista em Moçambique. Centrando-se nas figuras de Zedequias Manganhela e Eduardo Mondlane, a autora situa o seu trabalho na configuração e reconfiguração dos discursos no contexto da 'recuperação' de uma história nacional, relacionando-o também com o debate em torno da construção de figuras de heróis nacionais. O artigo situa-se quer no quadro de uma bistória oficial de Moçambique, quer no quadro da história institucional da Igreja Presbiteriana de Moçambiquel /Missão Suiça, à qual os dois protagonistas se encontravam ligados, desafiando o leitor a enfrentar as armadilhas da escrita biográfica.

João Paulo Borges Coelho, ao problematizar no seu texto como abrir a fábula, propõe-nos uma discussão sobre as complexidades associadas ao uso político do passado na construção da bistória em Moçambique. Como o autor sublinha, a narrativa fundadora da nação moçambicana permanece ancorada em episódios efabulados sobre a luta de libertação. Esta narrativa, desenvolvida a partir de um conjunto de oposições binárias e em noções específicas de experiência e subjetividade, está enraizada no depoimento de um conjunto de testemunhas desta luta, cuja autoridade moral nunca é questionada. Esta narrativa efabulada, refém de aliança intima entre o poder e o conbecimento sobre o passado recente, continua a procurar legitimar o exercício da autoridade em Moçambique, desafiando qualquer ação em prol da democratização da história. 
O número encerra com um depoimento pessoal de Aniceto Afonso, membro do Movimento das Forças Armadas de Portugal, estacionado na frente de guerra em Moçambique, à altura do golpe de 25 de abril de 1974. A análise atenta dos acontecimentos e atores envolvidos no golpe é reveladora da importância política deste, embora a consistência militar do grupo do MFA fosse mais frágil, como o autor argumenta. Uma leitura incontornável para uma melhor compreensão dos processos de descolonização que marcaram a transferência de poderes para os novos países independentes em 1975.

A rutura com o passado colonial está, como este número da revista expõe, repleta de episódios de continuidade com relações e projetos forjados nos anos que antecederam as independências. Estas reflexões, no seu conjunto, ecoam um apelo ao revisitar da história, sinal inequívoco do fracasso de qualquer metanarrativa nacional. Estes debates chamam a atenção para fraturas que atravessam as sociedades pós-coloniais e para a necessidade de um amplo processo de desvendamento de memórias de violência. O estudo dos processos que geraram estas fraturas é uma condição para a reconciliação e reconstituição dos países, e para um futuro de paz e progresso social. Como estes textos espelham, um conhecimento detalhado da história, assente em detalhes texturizados, e não apenas em generalizações ou versões higienizadas dos processos históricos, abre espaço para uma releitura e mesmo reinvenção destes processos, para imaginar o futuro de uma forma que evita a repetição dos erros e a imposição de uma leitura singular e simplista dos passados. As múltiplas memórias e esquecimentos sobre os episódios de violência colonial e das resistências nacionalistas permitem a afirmação de outras narrativas que desafiam as leituras hegemónicas, reacionárias, que paralisam qualquer vontade de mudança.

\section{Maria Paula Meneses}

\section{Referências bibliográficas}

Andrade, Mário de (1998), Origens do nacionalismo africano: continuidade e ruptura nos movimentos unitários emergentes da luta contra a dominação colonial portuguesa: 1911-1961. Lisboa: Publicações Dom Quixote.

Balandier, Georges (1951), "La situation coloniale: approche théorique", Cabiers Internationaux de Sociologie, 11, 44-79.

Meneses, Maria Paula (2008), "Mundos locais, mundos globais: a diferença da história", in Rosa Cabecinhas; Luís Cunha (orgs.), Comunicação intercultural: perspectivas, dilemas e desafios. Porto: Campo das Letras, 75-93. 
8| Maria Paula Meneses

Santos, Boaventura de Sousa (2006), A gramática do tempo. Para uma nova cultura política. Porto: Afrontamento.

Sarlo, Beatriz (2007), Tempo passado: cultura da memória e guinada subjetiva. Belo Horizonte: Editora UFMG. 